\title{
FORMATION OF NANOCRYSTALLINE STRUCTURE UPON SEVERE THERMOMECHANICAL PROCESSING AND ITS EFFECT ON THE SUPERPLASTIC PROPERTIES OF NICKEL BASE ALLOYS
}

\author{
V.A. Valitov \\ Institute for Metals Superplasticity Problems of the Russian Academy of Science \\ 39 Khalturin str., Ufa 450001 Russia
}

Keywords: structure, nickel, iron, alloy, temperature, deformation, processing, phase, superalloy, superplasticity.

\begin{abstract}
This paper is the systematic study of the mechanisms of structure formation of a wide range of nickel and nickel-iron based alloys with different types of strengthening $\left(\gamma+\gamma^{\prime} ; \gamma+\delta+\gamma^{\prime \prime}\right.$; $\left.\gamma+\gamma^{\prime}+\mathrm{Y}_{2} \mathrm{O}_{3}\right)$ in a wide temperature - strain rate interval of plastic deformation. Regimes of thermomechanical processing that provide stage-by-stage transformation of a coarse-grain structure into a microcrystalline $(\mathrm{MC})$ one, and further to nanocrystalline $(\mathrm{NC})$ structural state, have been established. The regularities of the effect exerted by the morphology of strengthening phase and processing conditions on the development of structure formation during hot, warm and cold deformation have been revealed. The correlation between the phase composition and the type of strengthening of superalloys with thermal stability of SMC and NC structures, and the possibility of manifestation of the effects of low temperature and high strain rate superplasticity (SP) have been revealed.

\section{Introduction}

Superplasticity is an important property for fabrication of parts from nickel based alloys [1-6]. For obtaining superplastic semi-manufactured structures mainly of high-heat-resistant nickel alloys such as IN100, Rene 95, N18 the technique known as Gatorising ${ }^{\mathrm{TM}}$ Forging Process [2] is widely used. Treatment by this method includes heating of the nickel alloy in the $\gamma^{\prime}+\gamma$ region below the recrystallization temperature and intensive deformation, for example, rolling or by compression molding with thickness reduction no less than $4: 1$. Due to the intense deformation of the material, heating up to recrystallization temperature takes place and causes the formation of the microduplex type structure. This method may be effective also for obtaining semimanufactured structures with SMC structure, for example, in the alloys made by mechanical alloying. The well-known method of equal channel angular pressing is not effective in the treatment of nickel-base alloys with the initial coarse-grained structure due to the low resistance of the die tooling [7]. The method of deformation with the use of Bridgman anvils is effective only for small-size laboratory samples up to $20 \mathrm{~mm}$ in diameter and $1-2 \mathrm{~mm}$ thickness $[7,8]$. One of the most effective methods of getting the large-size semi-manufactured structures with $\mathrm{MC}, \mathrm{SMC}$ or NC structure is isothermal multiple forging method which allows to maintain the original dimensions of the workpiece [9]. This process may be combined with other techniques such as pressing or rolling. This method is particularly effective in treating alloys of the Inconel 718 type and its analogs [10].
\end{abstract}


The expansion of manufacturing capability of SP effect due to the increase of strain rate and the decrease of the temperature of its manifestation becomes possible with the use of materials with submicrocrystalline (SMC) and nanocrystalline (NC) structures [1,7-12]. Such structures can be produced using severe plastic deformation (SPD) technique, such as multiple forging (MF) [810]. There is presently a substantial interest to the generation of such structural states and the study of their physical and mechanical properties [7-13]. However, there have been few previous studies of the formation of SMC and $\mathrm{NC}$ structures in complex nickel base alloys and the effect of these structures on SP behavior.

The goal of the present paper is to establish mechanisms for generating microcrystalline (MC), SMC and NC structures in nickel base alloys with different phase compositions, different morphology of strengthening phases during severe plastic deformation in a wide range of temperatures, and to evaluate the effect of these structures on SP properties.

\section{Materials and experimental procedure}

Samples for investigations of the precipitation hardened Superalloys 718 (Ni-19Cr-18Fe-5.1Nb3.1Mo-1.0Ti-0.5Al) and EP962 (Ni-13.1Cr-10.7Co-4.6Mo-3.4Nb-3.2Al-2.8W-2.6Ti-0.6Fe) were machined from hot deformed, $200 \mathrm{~mm}$ diameter, billets. Bulk samples $(40-80 \mathrm{~mm}$ in diameter and 10-12 mm long), were generated with MC, SMC and NC structures on 100 and 630 ton-force presses using severe thermomechanical processing (STMP) by MF on flat dies over the range of deformation temperatures $1100-600^{\circ} \mathrm{C}$ (EP962, alloy 718) [13-16]. The powder PDS-1 (Ni-10.1Cr-7.5W-6.8Al-1.2 $\mathrm{Y}_{2} \mathrm{O}_{3}$ ) alloy was produced by mechanical alloying and was in the form of $22 \mathrm{~mm}$ diameter rod from which the samples were machined [14]. Mechanical behavior of the alloys was investigated over a wide range of temperatures $\left(500-1270^{\circ} \mathrm{C}\right)$ and strain rates $\left(6.6 \cdot 10^{-5}-1.7 \cdot 10^{-1} \mathrm{~s}^{-1}\right)$. Flat samples, $10 \times 3 \times 2 \mathrm{~mm}$ in gauge length, and cylindrical samples, $5 \mathrm{~mm}$ in diameter and $25 \mathrm{~mm}$ in gauge length, were tensile tested in an INSTRON dynamometer. Transmission electron microscope (TEM) investigations were performed using a JEM-2000EX.

\section{Experimental Results}

\subsection{Generation of MC, SMC and NC structures by severe thermomechanical processing}

Initial state.

The microstructure of precipitation hardened alloys 718 and EP962 in the initial state is completely recrystallized and coarse-grained with grain sizes of $40-80 \mu \mathrm{m}$. The TEM studies of microstructures of these alloys $[13,15]$ have shown that within the alloy 718 matrix grains there are coarse $\delta$-phase plates, between which there is a uniform dispersion of coherent disk-type $\gamma^{\prime \prime}$ phase precipitates (Figure 1a). In the EP962, partially coherent precipitates of $\gamma^{\prime}$-phase, $0.5 \mu \mathrm{m}$ in size [11], are observed within the grains (Figure 2a).

Unlike these alloys, the powder dispersion-strengthened nickel base alloy, PDS-1, was produced by mechanical alloying; this generated a SMC structure with grain size of $0.8-1 \mu \mathrm{m}[14,17]$. This SMC structure is characterized by high density of dislocations both within the grains, and along grain boundaries (Figure 3). In order to establish the mechanisms of transformation of coarsegrained structure into a MC one, as well as of MC into a SMC structure, and further into a NC structure, the different structural states of samples subjected to isothermal upsetting were studied. 


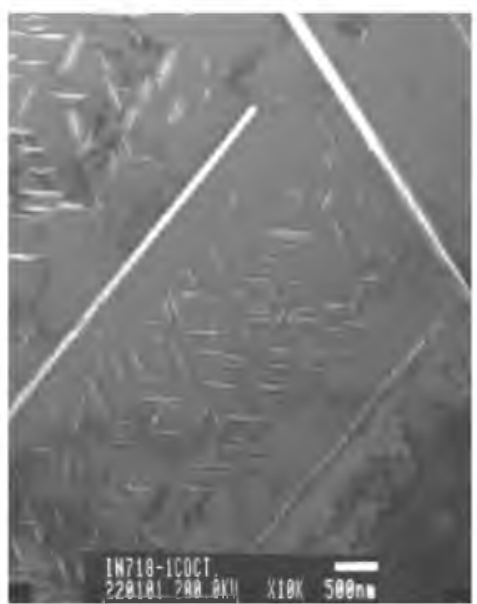

a

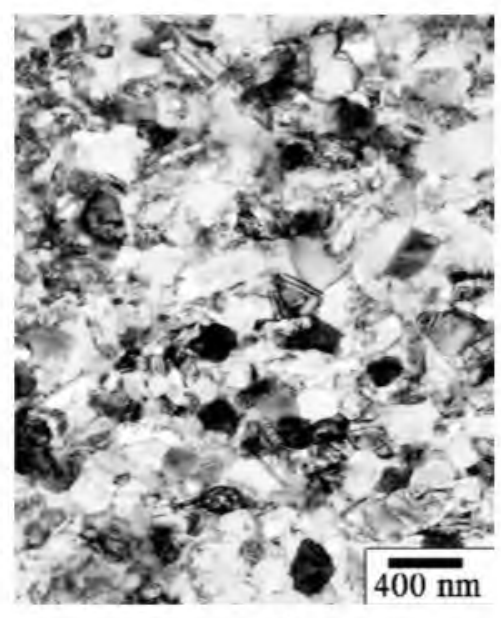

C
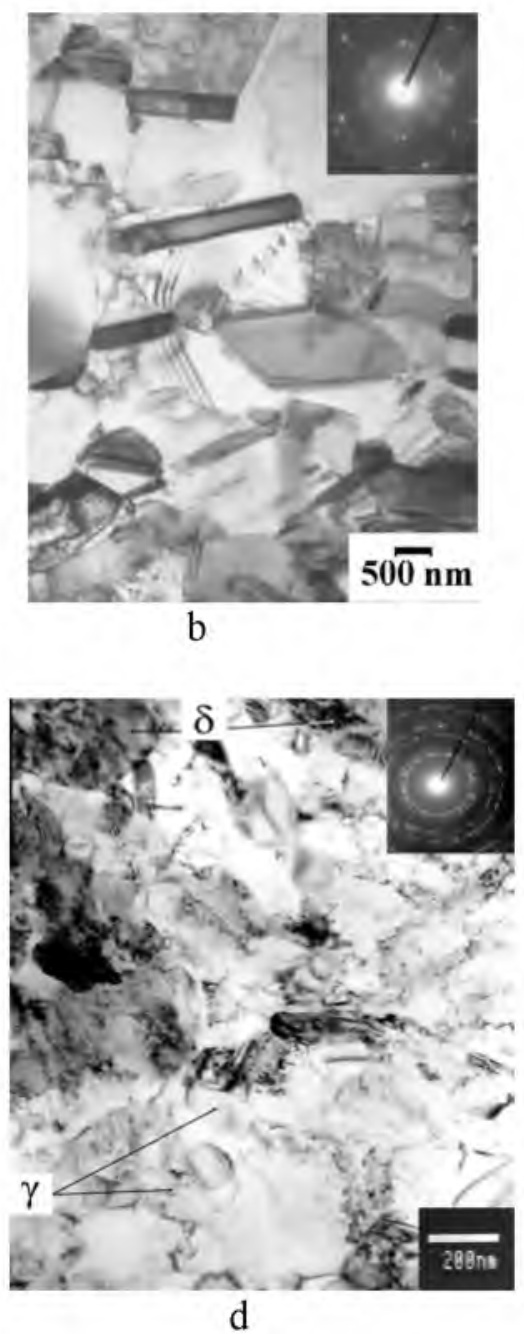

Figure 1. Microstructure of the alloy 718: a - Initial state - CG structure; b - MC structure; c - SMC structure; $d$ - NC structure.

\section{Formation of MC structure.}

The deformation of the precipitation hardened Superalloys 718 and EP962 is impossible at low homologous temperatures because these alloys have extremely low ductility in a coarse-grained (CG) state $[10,18-20]$. That is why the method of STMP was used. This technique includes fractional isothermal upsetting (or multiple isothermal forging) of samples using flat dies with a gradual step by step reduction in the temperature of processing with intermediate annealing at the deformation temperature $[16,21]$.

Thanks to this processing, the gradual step by step structure refinement from $\mathrm{CG}$ to $\mathrm{MC}$, from $\mathrm{MC}$ to SMC and further to a NC state, has been reached (Figures 4,5 ). The finer the structure, the higher ductility of the material was attained and the lower were the temperatures at which the alloys were strained. At the first stage the mechanisms of transformation of coarse-grained structure into a $\mathrm{MC}$ one were investigated in alloy 718 [21]. The analysis of mechanical behavior and features of microstructure evolution in the course of alloy 718 deformation within the temperature range of $850-950^{\circ} \mathrm{C}$ revealed that a $\mathrm{MC}$ structure is formed during the process of dynamic recrystallization accompanied by significant changes in the second phase morphology and its distribution (Figure 1). 

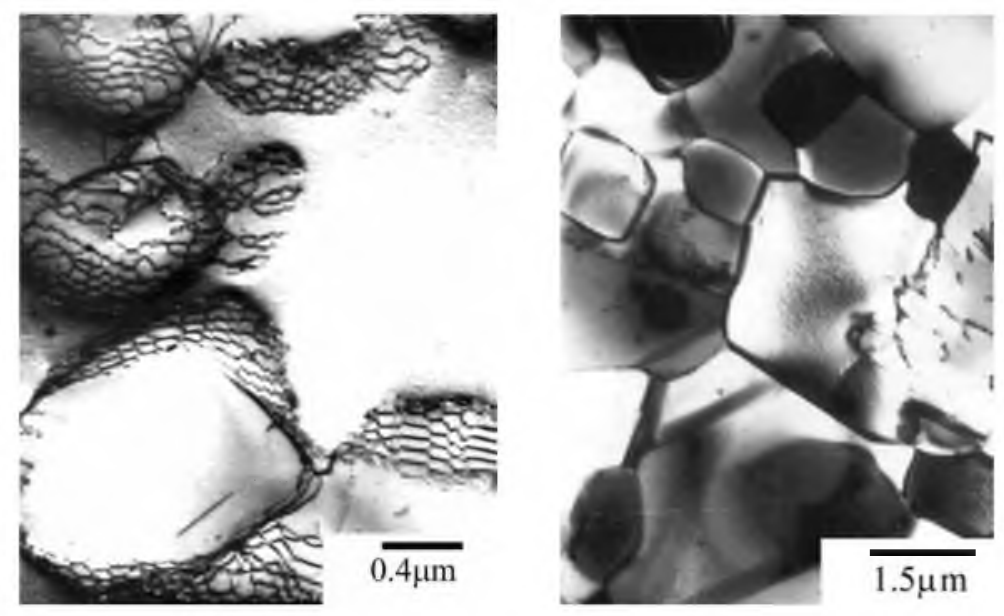

a

b
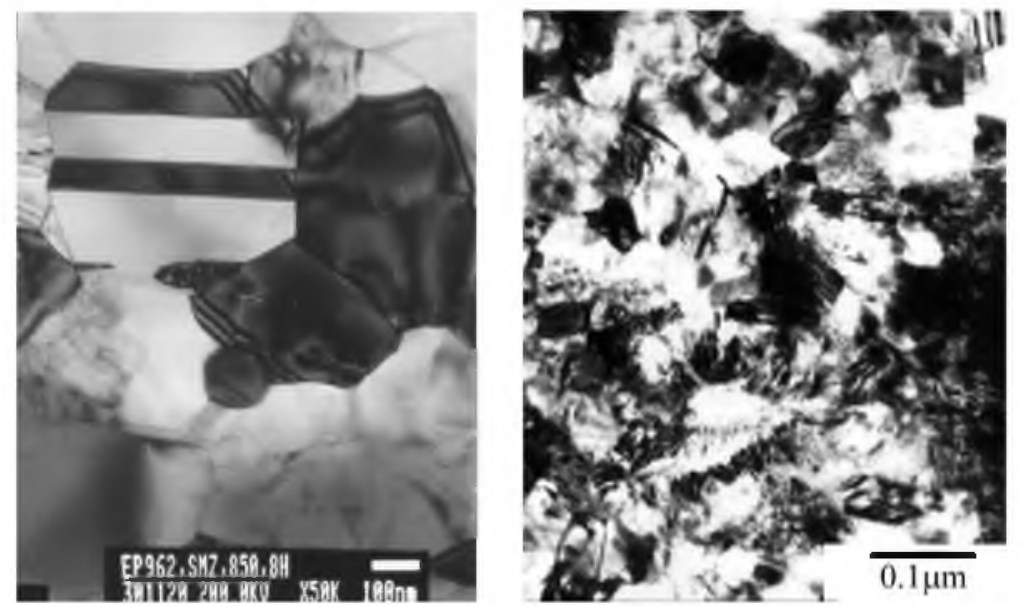

$\mathrm{c}$

d

Figure 2. Microstructure of the EP962 alloy after severe thermomechanical processing: a - CG structure, after annealing in $\gamma+\gamma^{\prime}$-region, 100 hours; b - MC structure; $\mathrm{c}-\mathrm{SMC}$ structure; $\mathrm{d}-\mathrm{NC}$ structure .

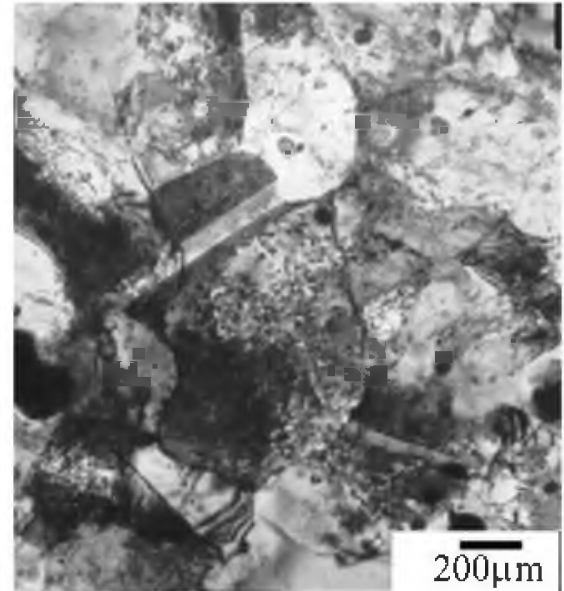

a

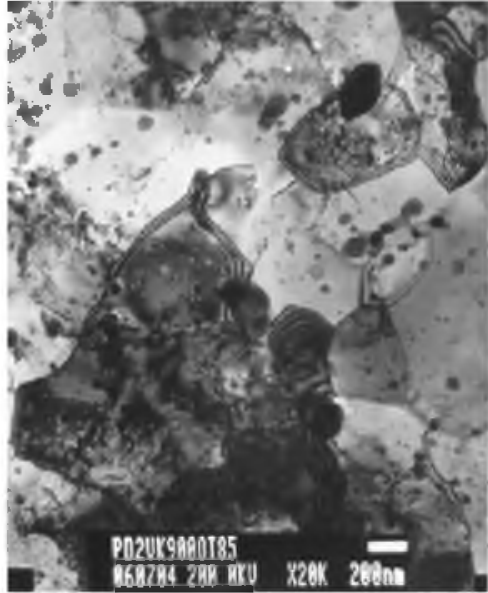

b

Figure 3. Microstructure of the alloy PDS-1: a) - Initial state, SMC structure;

b)- after severe thermomechanical processing, SMC structure $(0.5 \mu \mathrm{m})$. 
Development of intra-granular dislocation sliding results in the formation of dislocation walls within $\gamma$-phase grains and transverse dislocation walls in $\delta$-phase plates. An increase in strain leads to the transformation of matrix sub-grains into grains with high-angle boundaries. At the same time, there occurs the fragmentation of coherent $\delta$-phase plates and their transformation into smaller particles of round shape and non-coherent boundaries of general type. Severe thermo-mechanical processing at the temperatures ranging from 950 to $850^{\circ} \mathrm{C}$ generated the uniform MC structure in alloy 718 with grain sizes of $5-1 \mu \mathrm{m}$ within the whole sample's volume.

It might be well to point out that although there are significant differences in the morphology of plate-like $\delta$-phase precipitates in alloy 718 and $\gamma^{\prime}$-phase cuboidal ones in EP962, the detailed study of which was reported in [22], some mechanisms typical of both alloys are observed. The complex process of structure formation, associated with the cross-effect of dynamic recrystallization and the processes of solution and precipitation of the second phase, is also observed during hot deformation. Dynamic recrystallization also leads to the generation of subgranular structure and its gradual transformation into grains with high-angle boundaries, coherent or partially coherent $\gamma^{\prime}$-phase precipitates being transformed into non-coherent particles-grains with arbitrary orientation relative to matrix grains.

\section{Formation of SMC structure.}

At the second stage in order to achieve a finer grain SMC structure in, for example, alloy 718 , samples with processed MC structure were deformed. As the manifestation of SP is possible during hot deformation of alloy 718 in MC state, for generating SMC structure the temperature strain rate regimes were selected in order to provide the development of dynamic recrystallization. The character of $\sigma-\varepsilon$ dependencies and microstructural changes, the detailed description of which is given in [21], have been analyzed to show that SMC structure is formed at $600-700^{\circ} \mathrm{C}$ during dynamic recrystallization in $\gamma$-phase that is accompanied by further fragmentation of coarse $\delta$-phase plates, and also by the precipitation of finer plates and transformation of non-coherent interface boundaries of general type.

Structure evolution has been studied to show that deformation generates a mixed structure consisting of regions, in which sub-grains are formed, and also of regions where mainly the cells and bands of deformation origin are seen. Deformation at $700^{\circ} \mathrm{C}$ resulted in the generation of recrystallized grains of $0.2-5 \mu \mathrm{m}$ in size (Figure 1c).

Unlike alloy 718, fractional STMP of the EP962 alloy also produces SMC structure with grain sizes of $0.25-0.5 \mu \mathrm{m}[11,21]$, but in order to increase the recrystallized volume it is necessary to carry out long post-deformation annealing lasting from 2 to 8 hours (Figure 2c), while for the alloy 718 the post-deformation annealing can be combined with heating to accommodate the follow-up deformation. In comparison with alloy 718, neither cellular structure nor bands of the deformation origin were observed in the PDS-1 alloy at $700-800^{\circ} \mathrm{C}$. There occurs the generation of new recrystallized grains $\left(0.2-0.5 \mu \mathrm{m}\right.$ in sizes) and separate $\gamma^{\prime}$-grains with non-coherent boundaries of general type. The noteworthy feature of the SMC structure, formed during STMP in all alloys under study, is the high non-equilibrium nature of the structure associated mostly with the high dislocation density both within the grains and along the grain boundaries (Figures 1c, 2c). It should be noted that post-deformation annealing contributes to the formation of SMC structure with more equilibrium grain boundaries. 


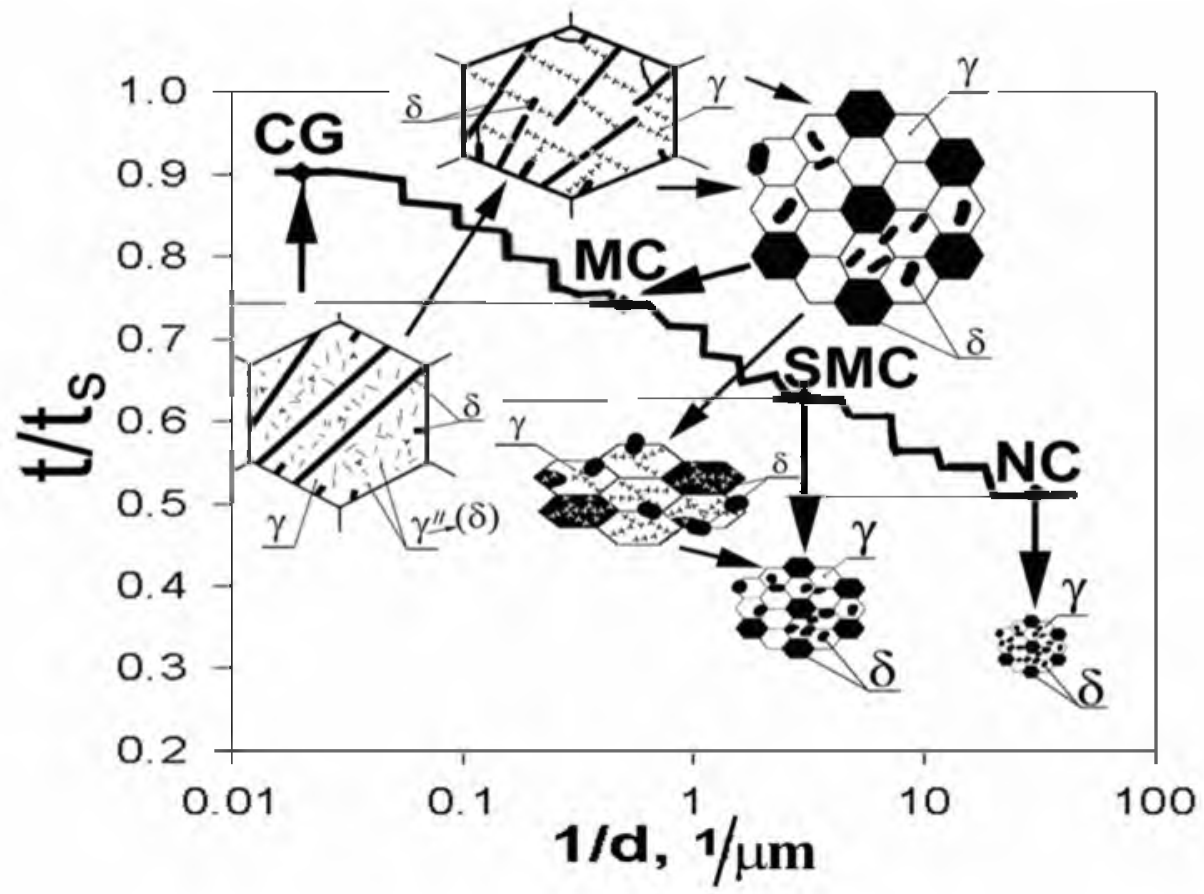

Figure 4. Model showing the three generic stages of transformation of a coarse-grained Superalloy 718 billet micro structure into an NC structure during STMP in the $\gamma+\delta$ region. $t_{\mathrm{s}}-\gamma^{\prime \prime}$-solvus temperature

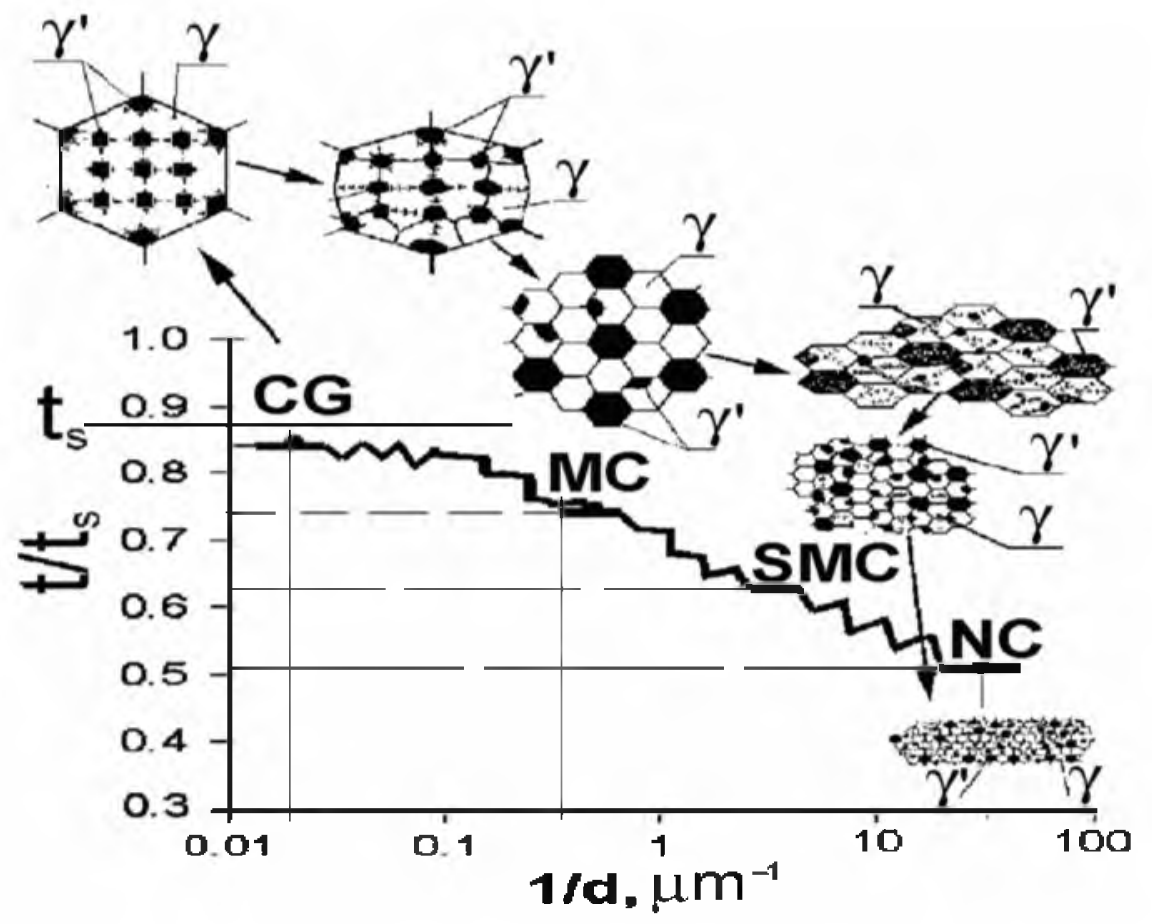

Figure 5. Model of microstructure transformation of EP962 alloy during STMP $\mathrm{t}_{\mathrm{s}}-\gamma^{\prime}$-solvus temperature 


\section{Formation of NC structure.}

The decrease in the deformation temperature to $575^{\circ} \mathrm{C}$ generated the structure with the finest grains in the alloy 718 with processed SMC structure. Analysis of the $\sigma-\varepsilon$ dependencies, presented in [21-23], showed that even at such low homologous temperature $\left(0.51 \mathrm{~T}_{\text {melt }}\right)$ there can develop dynamic recrystallization resulting in the generation of $\mathrm{NC}$ structure with an average grain size of $80 \mathrm{~nm}$ (Figure 1d). In the EP962 alloy, NC structure with grain sizes of $50 \mathrm{~nm}$ (Figure 2d) is generated at $700^{\circ} \mathrm{C}$ [22]. Further decrease in the deformation temperature at free upsetting on flat dies at a strain rate $10^{-4} \mathrm{~s}^{-1}$, even if an alloy with a structure close to a $\mathrm{NC}$ one is used, may lead to the occurrence of cold cracks. That is why at such low temperatures it is more appropriate to employ other deformation modes.

In particular, the technique of deformation by torsion under high quasi-hydrostatic pressure on Bridgman anvil at room temperature is very efficient. This technique generated NC structures in the alloys under study [22]. Microstructural studies of structure evolution in the alloys 718, EP962 and PDS- 1 alloys after deformations with strains from $\ln \mathrm{e}=1$ to $\ln \mathrm{e}=5.5$ showed that in both alloys there occurs the formation of cells that further, at deformation with strain lne $=5.5$, transform into grains, $20-50 \mathrm{~nm}$ in sizes ((Figure 6), with high-angle grain boundaries [22]. The feature of alloy 718 is the occurrence of bands of deformation origin, first - in one direction, and with increasing strain - in two directions. The occurrence of granular structure at earlier deformation stages can be attributed to the peculiarities of the PDS-1 alloy.

Thus, severe TMP of nickel base alloys with different phase compositions and different strengthening modes provides the generation of various structural states from $\mathrm{MC}$ up to $\mathrm{NC}$.

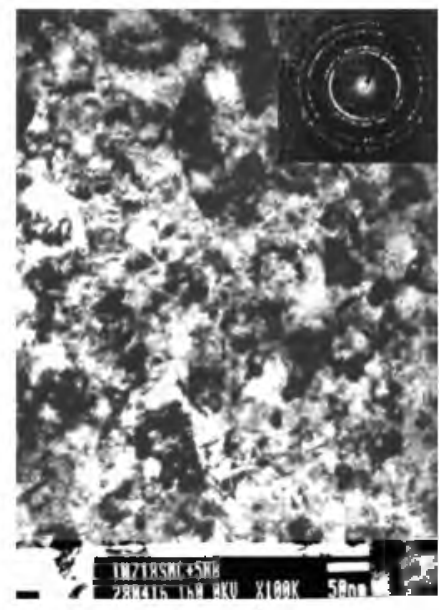

a

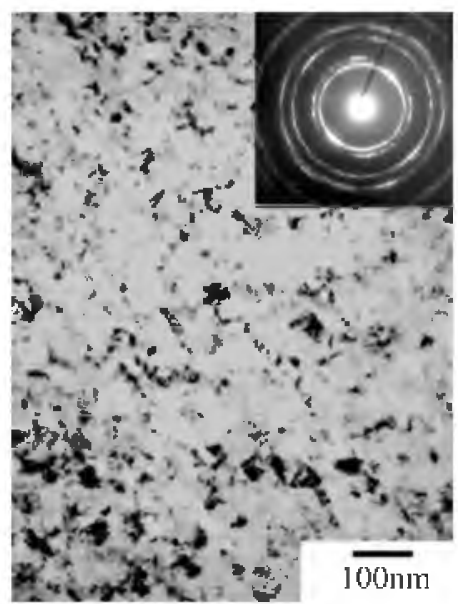

$\mathrm{b}$

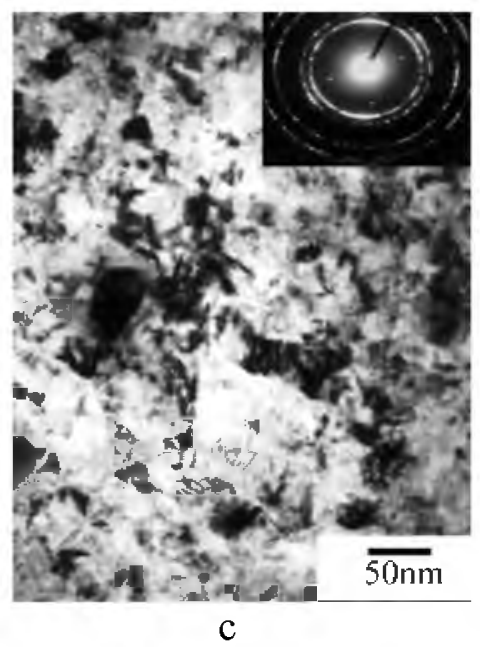

c

Figure 6. Microstructure of superalloys after severe plastic deformation to $\mathrm{e}=5$ :

a) alloy 718 ; b) EP962; c) PDS-1

\subsection{Superplasticity of nickel base alloys with MC, SMC and NC structures}

By varying STMP regimes it is possible to generate structural states with approximately equal grain sizes in the alloys under study. But the results of mechanical tensile tests showed that the difference in the chemical and phase compositions significantly influence their SP properties Besides, SP behavior of each particular nickel base alloy is to a great measure determined by initial grain sizes [24] (Table I). 
Table I. Characteristics of SP properties of nickel base alloys

\begin{tabular}{|c|c|c|c|c|c|c|c|}
\hline alloy & \multicolumn{2}{|c|}{$\begin{array}{l}\text { Size of grains } \\
\text { (particles), } \mu \mathrm{m}\end{array}$} & $\mathrm{t},{ }^{\circ} \mathrm{C}$ & $\begin{array}{l}\varepsilon \\
c^{-1}\end{array}$ & $\begin{array}{l}\sigma_{40}, \\
\mathrm{MPa}\end{array}$ & $\begin{array}{l}\delta \\
\%\end{array}$ & $\mathrm{~m}$ \\
\hline \multirow{12}{*}{$\stackrel{\infty}{\sim}$} & $\gamma$-phase & $\delta$-phase & & & & & \\
\hline & 6 & & 980 & $25 \cdot 10^{-4}$ & 70 & 514 & $0,5[25]$ \\
\hline & \multirow{4}{*}{$1-2$} & \multirow{4}{*}{$0.15-0.6$} & 950 & $5.5 \cdot 10^{-4}$ & 63 & 660 & 0.6 \\
\hline & & & 800 & $1.5 \cdot 10^{-4}$ & 134 & 390 & 0.33 \\
\hline & & & 700 & $3 \cdot 10^{-4}$ & 563 & 170 & 0.2 \\
\hline & & & 650 & $5.5 \cdot 10^{-4}$ & 742 & 85 & 0.1 \\
\hline & \multirow[t]{4}{*}{0.3} & \multirow[t]{4}{*}{$0.1-0.6$} & 900 & $5.5 \cdot 10^{-4}$ & 65 & 790 & 0.6 \\
\hline & & & 800 & $1.5 \cdot 10^{-4}$ & 87 & 1095 & 0.54 \\
\hline & & & 700 & $3 \cdot 10^{-4}$ & 224 & 700 & 0.41 \\
\hline & & & 650 & $5.5 \cdot 10^{-4}$ & 514 & 370 & 0.3 \\
\hline & \multirow{2}{*}{\multicolumn{2}{|c|}{$0.08-0.1$}} & 600 & $1.5 \cdot 10^{-4}$ & 414 & 350 & 0.37 \\
\hline & & & 550 & $0.9 \cdot 10^{-4}$ & 1017 & 160 & 0.25 \\
\hline \multirow{7}{*}{ 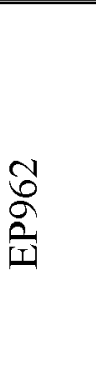 } & $\gamma$-phase & $\gamma^{\prime}-$ phase & & & & & \\
\hline & & & 1075 & $1.33 \cdot 10^{-3}$ & 50 & $>550$ & 0.6 \\
\hline & 5.5 & 2.5 & 950 & $1.33 \cdot 10^{-3}$ & 120 & $>500$ & 0.3 \\
\hline & 2.5 & 1.3 & 875 & $1.33 \cdot 10^{-3}$ & 349 & 116 & 0.25 \\
\hline & & & 950 & $1.33 \cdot 10^{-2}$ & 144 & 252 & 0.43 \\
\hline & \multicolumn{2}{|c|}{0.25} & 875 & $1.33 \cdot 10^{-3}$ & 187 & 337 & 0.39 \\
\hline & & & 800 & $3.3 \cdot 10^{-4}$ & 350 & $>550$ & 0.3 \\
\hline \multirow{2}{*}{ in } & \multirow{2}{*}{\multicolumn{2}{|c|}{0.5}} & 800 & $3.3 \cdot 10^{-4}$ & 71 & 240 & 0.35 \\
\hline & & & 1250 & $8.3 \cdot 10^{-2}$ & 19 & 200 & 0.5 \\
\hline
\end{tabular}

The reduction of grain sizes in precipitation-hardened alloys 718 and EP962 provides a significant expansion of the temperature - strain rate interval of SP. Structure refinement towards SMC and NC sizes allows the manifestation of low-temperature SP effect (Figures 7-9). Thus, the alloy 718 alloy with $\mathrm{NC}$ structure reveals SP features even at $\mathrm{T}=600^{\circ} \mathrm{C}[10,21]$.

The dispersion-hardened alloy PDS-1 reveals the features of high strain rate SP even in the starting state $(\mathrm{d}=0.8 \mu \mathrm{m})$ at $\mathrm{T}=1200-1275^{\circ} \mathrm{C}$. After TMP, it reveals the features of both high strain rate and low-temperature SP [24]. At high homologous temperatures (higher than the temperature of $\gamma^{\prime}$-phase solvus), high strain rate SP is provided by the high stability of SMC structure resulting from the presence of high-melting particles of yttrium phase. Presence of a large number of $\gamma^{\prime}$-phase grains with non-coherent interface boundaries of general type provides the occurrence of low-temperature SP. With increasing temperature from 1100 to $1275^{\circ} \mathrm{C}$, SP optimum properties shifts to the region of higher strain rates (by $0.5-1$ orders).

The values of plasticity in the PDS-1 alloy are lower than in the precipitation-hardened alloys. This is probably due to the presence of high-melting particles of yttrium phase at grain 
boundaries that accelerate the development of pore formation during superplastic deformation, especially at transverse boundaries.

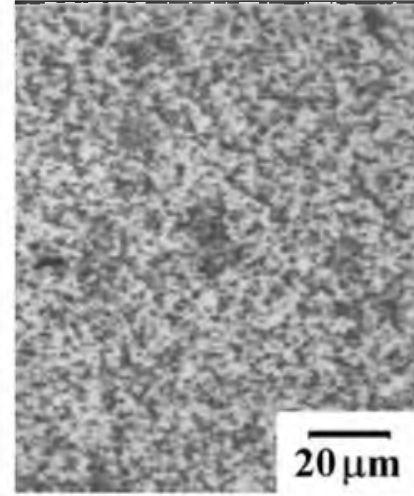

a

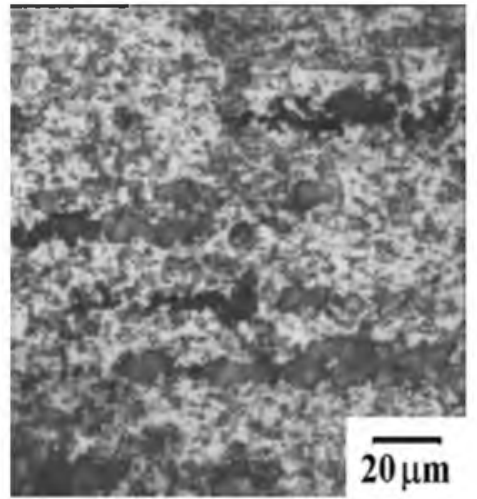

b

Figure 7. Microstructure of Alloy 718 with SMC subjected to tension at $900^{\circ} \mathrm{C}$ with strain rate $5.5 \times 10^{-4} \mathrm{~s}^{-1}$ : (a) sample's gauge zone; (b) near sample's grip section

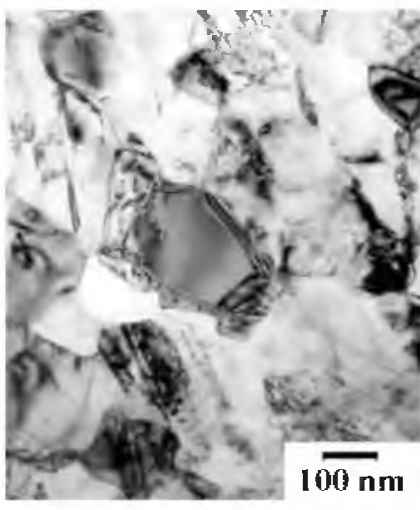

a

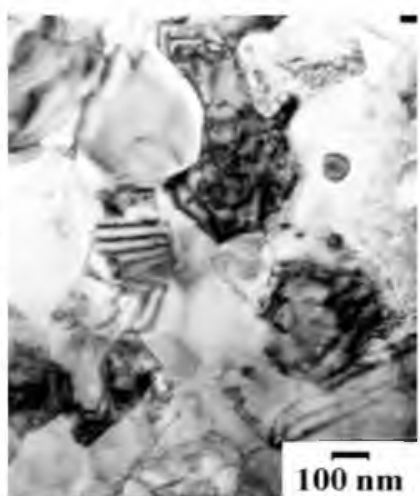

b

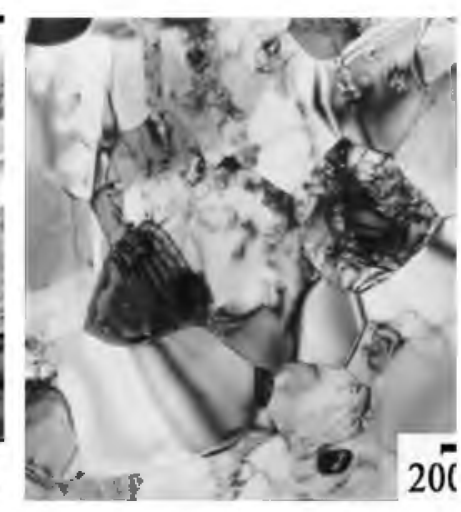

$\mathrm{C}$

Figure 8. Microstructure of superalloys structure subjected to tension: alloy 718 with NC structure at $550^{\circ} \mathrm{C}$ with strain rate $0.9 \times 10^{-4} \mathrm{~s}^{-1}(\mathrm{a})$; at $600^{\circ} \mathrm{C}$ with strain rate $3 \times 10^{-4} \mathrm{~s}^{-1}(\mathrm{~b})$; alloy EP962 with SMC structure at $800^{\circ} \mathrm{C}$ with strain rate $3.3 \times 10^{-4} \mathrm{~s}^{-1}$ (c).

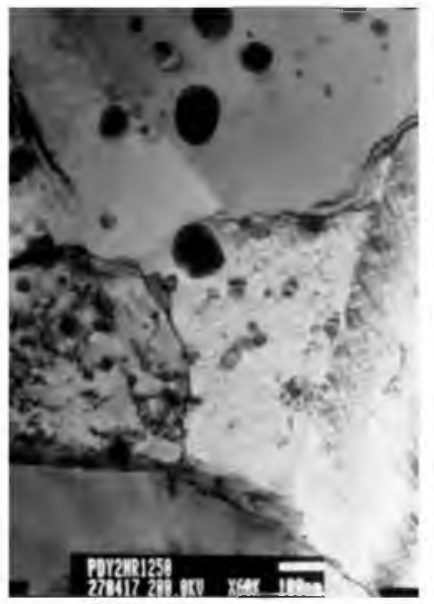

a

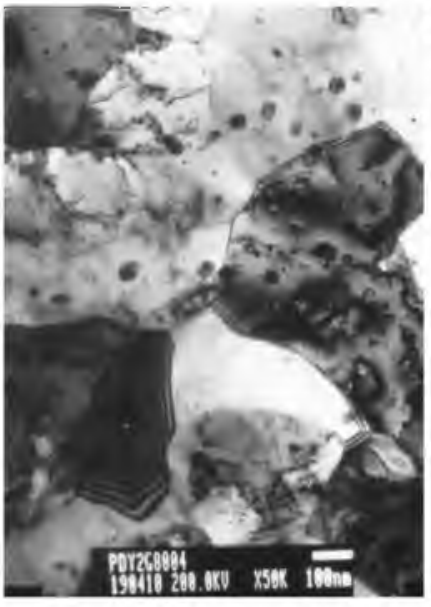

b

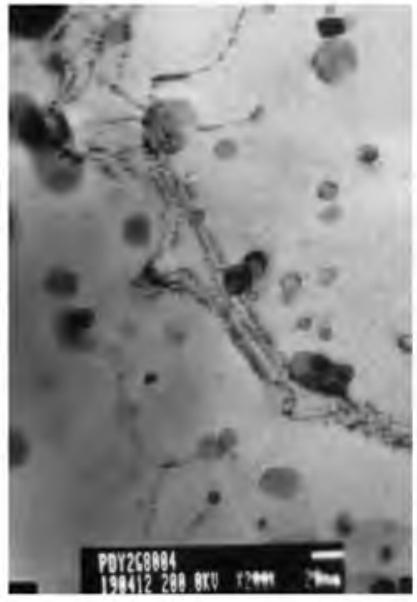

$\mathrm{c}$

Figure 9. Microstructure of alloy PDS-1 with SMC structure subjected to tension:

at $1250^{\circ} \mathrm{C}$ with strain rate $8.3 \times 10^{-2} \mathrm{~s}^{-1}$ (a); at $800^{\circ} \mathrm{C}$ with strain rate $3.3 \times 10^{-4} \mathrm{~s}^{-1}$. (b, c). 
Pore formation is observed in all alloys (Figure 10). If in the alloy 718 alloy pores are revealed mostly close to the failure zone, in the EP962 and PDS-1 - mainly in the vicinity of carbide particles [23]. Change of density in EP962 during SP deformation is also evidently connected with pore formation.

Thus, the correlation between phase composition and the type of strengthening of superalloys with thermal stability of SMC and NC structures, and the possibility of manifestation of the effects of low temperature and high strain rate SP has been revealed.

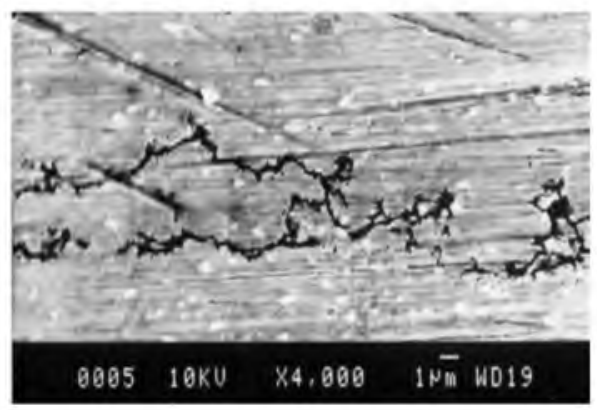

a

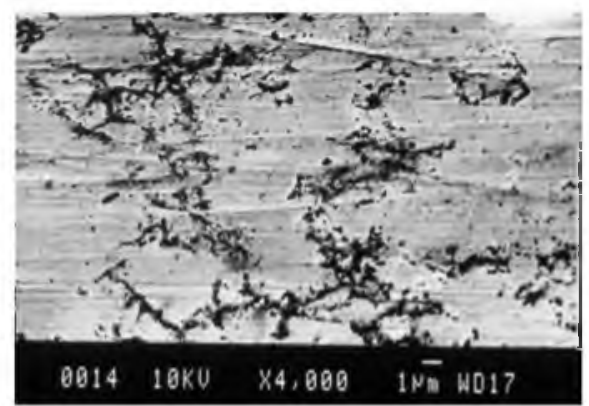

$\mathrm{b}$

Figure 10. Microstructure (near ruptured zone) of alloys EP962 (a) and PDS-1 (b) with $\mathrm{SMC}$ structure subjected to tension at $800^{\circ} \mathrm{C}$ with strain rate $3.3 \times 10^{-4} \mathrm{~s}^{-1}$.

\section{Summary and Conclusions}

This paper summarizes the results of long-term (over 25 years) systematic studies of structure evolution processes during thermo-mechanical treatment as well as superplastic behavior of nickel alloys with different phase compositions and types of hardening $\left(\gamma^{\prime} ; \gamma^{\prime \prime}+\delta, \gamma^{\prime}+\mathrm{Y}_{2} \mathrm{O}_{3}\right)$. On the basis of the established trends of microstructure evolution during plastic deformation, a universal methodological approach base on thermo-mechanical treatment was developed to achieve stepwise refinement of the coarse-grained structure starting from the formation of the microcrystalline structure of microduplex type, through the sub-microcrystalline structure down to the nanocrystalline structure.

It was established that in the precipitation-hardened superalloys with sub-microcrystalline and nanocrystalline structure the effect of superplasticity is observed at temperatures $200-350^{\circ} \mathrm{C}$ lower than in materials with microcrystalline structure. At the same time the level of the flow stress decreases by a factor of 1.5-2.0 and the strain rate increases by 1.0-1.5 orders of magnitude. It was shown that in the nickel alloys with ultra-small grains strengthened by the $\mathrm{Y}_{2} \mathrm{O}_{3}$ refractory particles (PDS-1 type alloy), a high thermal stability of the structure is achieved and for this reason such alloys are characterized not only by the low temperature superplasticity but also high-speed superplasticity up to a temperature close to the solidus temperature.

The author expresses his deep gratitude to Prof. O.A. Kaibyshev and Dr. Hub. F.Z. Utyashev for their guidance when doing research. He also thanks the staff of IMSP and foreign colleagues, in particular, of the General Electric company for the assistance in conducting joint experiments and for the discussions. The result of this fruitful cooperation were published in the joint research papers presented in the list of references. 
This work was partially supported by the Russian Foundation for Basic Research (RFBR) grant No 13-08-12200 $\backslash 14$.

\section{References}

1. Kaibyshev O. A., Superplasticity of Alloys, Intermetallides and Ceramics. Berlin: Springer Verlag, (1992), 316.

2. Athey R.L., Moore J.B. Progress Report on the Gatorising ${ }^{\mathrm{TM}}$ Forging Process. National Aerospase Engineering and Manufacturing meeting, Los Angeles. (1975), 1-11.

3. Brown E.B., Boetner R.C., Ruchle D.L. Minigrein Processing of Nickel-base Alloys. Proc. 2nd Int. Conf. AIME.---New York, NY. -in Superalloys - Processing. (1972), 1-12.

4. Kobayashi M. Novel Processing Methods for Superplastic Alloys. Superplasticity and Superplastic Forming . Proc. Conf. Superplasticity and Superplastic Forming. Blain, (1988), 271 $-281$.

5. Pilling J. Proc. Gonf. Superpiasticity and Superplastic Forming, Blain. (1988). 475-489.

6. Immarigeon J.-P., Floyd P.H. Microstructural Instabilities During Superplastic Forging of a Nickel-base Superalloy Compact. Met. Trans. (1981), V.12A, 1177-1186.

7. Valiev R.Z. and Aleksandrov I.V. Nanostructured Materials Obtained By Severe Plastic Deformation. Logos, Moscow, (2000), 272

8. Kaibyshev O.A., Utyashev F.Z. Superplasticity:Microstructural Refinemant and Superplastic Roll Forming)». Futurepast. Arlington, Virginia USA, (2005), 386.

9. Salishcev G., Zaripova R., Galeev R., Valiakhmetov O. Nanocrisalline Structure Formation During Severe Plastic Deformation in Metals and Their Deformation Behavior. Nanostructured Materials, 6 (1994), 913-916.

10.Valitov V. A., Mulyukov R. R., Gigliotti M. F. X., Subramanian P. R. Severe Thermomechanical Processing as an Effective Method for the Preparation of Bulk and Sheet Nanostructured Semifinished Products from Nickel Alloys 718 and 718Plus. In Book Superalloys 2008, Roger C. Reed, Kenneth A. Green, Pierre Caron, Timothy P. Gabb, Michael G. Fahrmann, Eric S. Huron, and Shiela A. Woodard, editors. - TMS (2008), 325-332.

11. Valitov V.A.,Salishchev G.A., Mukhtarov S.K. Izv. RAN, Metally. (1994), No. 3, 127-131.

12. Valiev R.Z., Korznikov A.V., Mulyukov R.R. Structure and Properties of Metallic Materials with Submicrocrystalline Structure. Fiz. Met. Metalloved. (1992), V.6, 70-86.

13. Valitov V.A., Utyashev F.Z., Mukhtarov Sh.Kh. Proc. of the 2nd Intern. Conf. "Towards Innovation in Superplasticity", Mat. Sci. For. (1999), V. 304-30, 79-84.

14. Valitov V.A., Salishchev G.A., Mukhtarov Sh.Kh. ICSAM97, Mat. Sci. For. (1997), V. 243$245,557-562$.

15. Valitov V.A., Bewlay B.P., Mukhtarov Sh.Kh., Kaibyshev O.A., Gigliotti M.F.X. Proceeding of MRS Fall Meeting "Superplasticity Current Status And Future Potential", USA Mat. Res. Soc. Symp. Proc. (2000), V. 601, 43-48. 
16. Utyashev F.Z., Kaibyshev O.A., Valitov V.A. European Patent EP 0909339 B1 (2001).

17. Salishchev G.A., Valiakhmetov O.R., Valitov V.A., Mukhtarov Sh.Kh. ICSAM-94, Mat. Sci. For. (1994). V.170-17, 121-130.

18. Kaibyshev O.A., Valitov V.A., Salishchev G.A. Patent RU No. 2041284. (1995).

19. Bewlay B.P., Valitov V.A., Kaibyshev O.A., Mukhtarov Sh.Kh., Hardwicke C.U., Gigliotti M.F.X.. Proc. of Symp. of TMS. Indiana, USA. A Publication of TMS. (2001), 175-185.

20. Kaibyshev O.A., Valitov V.A., Salishchev G.A.. Phys. Met. Metallogr. (1993), V.75, 409414).

21. Valitov V.A., Mukhtarov Sh. Kh., Raskulova Yu.A., Fiz. Met. Metalloved. (2006), No. 1, 105-113.

22. Valitov V.A., Kaibyshev O.A., Mukhtarov Sh. Kh., Gajnutdinova N.R. . Proc. of the First Joint Intern. Conf. "Recrystallization and Grain Growth", Springer-Verlag. (2001), 563-568.

23. Valitov V.A., Kaibyshev O.A., Mukhtarov Sh. Kh., Bewlay B.P., Gigliotti M.F.X. ICSAM2000 Orlando, USA. Mat. Sci. For. (2001), 417-424.

24. Salishchev G.A., Valitov V.A., Borzov A.B., Ivanova E.V., Mukhtarov Sh. Kh. Izv. VUZov. Chernaya Metallurgia. (2002), No. 2, 37-41.

25. Mahoney M.W. Superplastic properties of alloy 718. Superalloy 718 - Metallurgy and Applications, ed. by E.A. Loria. - The Minerals, Metals \& Materials Society. (1989), 391-405. 